\title{
ANÁLISE SOBRE A INCIDÊNCIA DE PRAZO DECADENCIAL AO TESTAMENTO HOLÓGRAFO SIMPLIFICADO
}

\author{
Rafael da Silva Santana ${ }^{1}$
}

Resumo: O objetivo deste artigo é analisar o instituto do testamento hológrafo simplificado, novidade trazida ao nosso sistema jurídico pelo artigo 1.879 do Código Civil de 2002, e entender os pontos convergentes e distinções desta modalidade de testamento particular com os testamentos especiais, para, por fim, responder ao seguinte problema: o prazo decadencial previsto para os testamentos especiais se amolda à esta espécie testamentária?

Palavras-chave: Testamento. Testamento particular. Testamento Hológrafo Simplificado. Testamentos Especiais. Prazo Decadencial.

\section{ANALYSIS OF THE IMPACT OF THE DECADENTIAL DEADLINE TO THE SIMPLIFIED HOLOGRAPH TESTAMENT}

\begin{abstract}
The purpose of this article is to analyze the institute of the exceptional private testament, novelty brought to our legal system by article 1.879 of the Civil Code of 2002, and to understand the points of convergence and distinctions of this modality of private testament with the special wills, in order to, finally, answer to the following problem: does the decadential term provided for special wills conform to this testamentary species?
\end{abstract}

Keywords: Testament. Private testament. Exceptional Private Testament. Special Wills. Decadential Term.

\footnotetext{
${ }^{1}$ Advogado, pós-graduado, lato sensu, em direito processual civil pela Faculdade Baiana de Direito, mestrando pela Faculdade de Direito da Universidade Federal da Bahia. E-mail: rssantana.adv@gmail.com. Postal: Rua Ewerton Visco, 290, sala 801, Boulevard Side Empresarial. CEP 41.820-022, Salvador, Bahia, Brasil.
} 


\section{INTRODUÇÃO}

É hodiernamente sabido que o brasileiro pouco se vale dos métodos de planejamento sucessório, e, em especial, do testamento. Alguns estudiosos afirmam que o receio da morte e a cultura latina sejam fatores que contribuem para a baixa adesão à via testamentária como modalidade lícita de planejamento sucessório. Sem embargo, são taxativos em afirmar que o excesso de solenidade e o custo da opção negocial se apresentam como entraves à elaboração do testamento.

Observada a resistência popular à tecnologia jurídica proposta, cumulado com a necessidade de atualizar as diretrizes de um dos livros do Código Civil que menos sofreu influência do novo pensar sobre o direito privado, a doutrina vem buscando respostas para os problemas instrumentais e principiológicos experimentados no campo do direito sucessório, na tentativa de harmonizá-lo com os outros componentes do código.

Dentre os esforços teóricos que contribuem para que o instituto do testamento não caia em desuso, ganha especial relevo o movimento doutrinário, com impacto legislativo, que estuda meios de diminuir a burocracia do negócio jurídico em estudo, sem prejudicar sobremaneira a segurança esperada na prática do ato. Neste cenário, a experiência estrangeira foi preponderante para a inclusão de nova modalidade testamentária no ordenamento jurídico pátrio, qual seja, o testamento hológrafo simplificado, também intitulado de testamento particular excepcional.

Das modalidades de testamento, mesmo se consideradas as ordinárias e especiais, o hológrafo simplificado, previsto no artigo 1.879 do Código Civil, é o que reúne a menor ritualística na confecção do instrumento de última vontade.

A despeito da simplicidade, desde a inserção do instituto no ordenamento jurídico nacional, há diversas críticas sobre a alocação espacial do testamento holográfico simplificado no Código, atraindo dúvidas sobre, por exemplo, a natureza jurídica do instituto, se modalidade testamentária especial ou ordinária. Fruto desta dúvida, igualmente se questiona a existência de prazo decadencial incidente sobre o instituto e, se houver, qual seria este.

Na tentativa de lançar novas luzes sobre o tema, durante a VII Jornada de Direito Civil foi aprovado o enunciado $\mathrm{n}^{\circ}$ 611, que delibera sobre a incidência do prazo decadencial de noventa dias, próprio dos testamentos especiais, ao testamento particular excepcional.

Sem pretensão alguma de esgotar o tema, intenta-se iniciar a discussão para aclarar os fundamentos jurídicos, legais e principiológicos, com a finalidade de investigar a natureza do 
testamento hológrafo simplificado, bem como analisar a possibilidade de incidência do prazo decadencial típico dos testamentos especiais sobre esta modalidade testamentária.

\section{LINHAS GERAIS SOBRE O TESTAMENTO HOLÓGRAFO SIMPLIFICADO}

Ao definir testamento, Tartuce (2016) revela que este é, em sede de Direito das Sucessões, a principal forma de expressão e exercício da autonomia privada, como típico instituto mortis causa. Além de constituir o cerne da modalidade sucessão testamentária, por ato de última vontade, o testamento também é a via adequada para outras manifestações da liberdade pessoal (TARTUCE, 2016). As afirmações acima esposadas encontram fundamento nas valiosas lições de Pontes de Miranda, reanimadas por Hijaz, cuja transcrição se mostra oportuna.

O testamento (diz-se) é ato pelo qual a vontade de um morto cria, transmite ou
extingue direitos. Porque "vontade de um morto cria”, e não "vontade de um vivo,
para depois da morte”? Quando o testador quis, vivia. Os efeitos, sim, como serem
dependentes da morte, somente começam a partir dali. Tanto é certo que se trata de
querer de vivo, que direitos há (excepcionalíssimos, é certo), que podem partir do ato
testamentário e serem realizados desde esse momento. Digamos, pois, que o
testamento é o ato pelo qual a vontade de alguém se declara para o caso de morte, com
eficácia de reconhecer, criar, transmitir, ou extinguir direitos (PONTES DE
MIRANDA, 1972, apud TARTUCE, 2011, p. 1.248).

Sem perder de vista a natureza jurídica do testamento, que na classificação adotada por Veloso (2004), é de negócio jurídico personalíssimo, unilateral, formal ou solene e revogável², e complementada por Gonçalves (2012, p. 231) ao notar o caráter gratuito do instituto, é instituto próprio do direito sucessório que tem como objetivo transmitir, quando do evento morte do autor do testamento, elementos patrimoniais e extrapatrimoniais, ao eleito, respeitada a fração dispositiva do patrimônio.

Dentre as hipóteses de testamento previstas no Código Civil, alocadas entre os artigos 1.862 e 1.896, voltaremos nossa atenção a examinar neste artigo a hipótese excepcional do testamento particular.

Modalidade testamentária trazida ao ordenamento jurídico como uma das inovações do Código Civil de 2002, o testamento hológrafo simplificado é uma modalidade excepcional de testamento particular. Alheio ao formalismo que norteia as demais formas de dispor do

\footnotetext{
${ }^{2}$ Sobre a natureza jurídica do testamento, Zeno Veloso é categórico em afirmar que se trata de negócio jurídico, e não de ato jurídica strictu senso, porque a manifestação de vontade do disponente não é mero pressuposto do qual decorrem efeitos jurídicos necessários, pré-estabelecidos, mas, além disto, a vontade é de resultado, prescrevendo, indicando, ordenando diversas consequências. (VELOSO, 2004).
} 
patrimônio via testamento, esta hipótese se valida a partir da verificação de uma situação excepcional, que impossibilitaria a formulação de instrumento de última vontade por outro mecanismo, ordinário ou especial, identificando-a no meio físico da transmissão da manifestação de vontade, escrito pelo particular.

Assim, a excepcionalidade que justifica a utilização desta via testamentária simplificada deve ser mencionada no próprio instrumento, como forma de preencher o requisito legal previsto no artigo 1.879 do código em comento (GONÇALVES, 2012, p. 290).

O direito positivado não delimitou as hipóteses que venham a autorizar a feitura do testamento nesta modalidade (DIAS, 2014), mas, na tentativa de contribuir com a identificação dos cenários onde o instituto possa ser aplicado, Rodolfo Pamplona e Pablo Stolze trazem como exemplo, situações de risco verificadas em retiro espiritual longínquo, momentos anteriores ao cometimento do suicídio etc. (GAGLIANO, 2016, p. 311). Outras situações são também traçadas por (VELOSO, 2004) como nas enchentes, incêndios e em locais sem comunicação.

Dos exemplos retro suscitados é possível extrair a característica mais marcante do instituto em apreço, qual seja, representar a única hipótese admitida no direito brasileiro que possibilita a prática do ato de disposição testamentária sem que haja a presença de testemunhas (VELOSO, 2004). Ainda que com procedimento reduzido, as vias testamentárias especiais exigem a presença de testemunhas. Duas são necessárias para validar o testamento marítimo e aeronáutico, conforme prevê o artigo 1.888 do Código Civil e, para o militar, por força do artigo 1.893, duas testemunhas caso o autor do testamento saiba escrever, e, em não sabendo, três.

Por se tratar de modalidade de testamento particular, o hológrafo simplificado se submete à confirmação judicial. A análise jurisdicional, que surge por provocação dos herdeiros, e que se dá através de procedimento de jurisdição voluntária, previsto nos artigos 735 a 737 do Código de Processo Civil vigente, se limitará a analisar aspectos formais do testamento, ressalvadas as hipóteses de impugnação pelos demais herdeiros. Santos (2016, p. 522) ensina que: “[...] tanto a inquirição das testemunhas quanto as possíveis impugnações dos interessados devem cingir-se à validade formal do testamento, não competindo ao juiz examinar seus requisitos intrínsecos, o que é da competência do juízo do inventário”. Em razão de não ser exigida a presença de testemunhas, a única atividade jurisdicional necessária à validação do testamento hológrafo simplificado é a verificação da ocorrência de situação excepcional ${ }^{3}$.

\footnotetext{
${ }^{3}$ Em que pese serem poucos os casos semelhantes submetidos ao controle jurisdicional, há julgado paradigmático que reflete o entendimento jurisprudencial, senão vejamos: “Testamento. Particular. Excepcional. Documento
} 
Neste sentido, o juízo competente fará análise dos elementos extrínsecos do testamento hológrafo simplificado, bastando-lhe investigar se houve a descrição do fato excepcional no instrumento particular, bem como se, uma vez descrito, tal evento é, de fato, excepcional de modo que impossibilitaria a confecção do ato de disposição patrimonial pós morte por outro meio típico, ainda que especial (DIAS, 2015, p. 376-377).

Neste diapasão, a sentença que decide sobre a validade do testamento possui inequívoca natureza constitutiva. Uma vez confirmados os elementos extrínsecos do instrumento, o poder judiciário está autorizado a seguir com o cumprimento do testamento, exercendo, a partir daí a atividade mandamental típica das demais hipóteses de testamentos ordinários. ${ }^{4}$

Superada a conceituação perfunctória do instituto do testamento hológrafo simplificado, há na doutrina dúvidas que permanecem pujantes desde a vigência do instituto até os dias atuais. Inequivocamente esta é uma modalidade excepcional de testamento particular, mas seria ela uma hipótese de testamento ordinário? E se não for, reúne elementos que a façam similar às

lavrado de próprio punho, quando da eminência de o disponente, temeroso de vir a falecer, ser submetido a cirurgia. Validade. Excepcionalidade devidamente declarada, consistente no temor da morte quando do procedimento cirúrgico. Ausência de identificação das testemunhas. Irrelevância. Dispensa das mesmas pelo art. 1.879 do CC. Recurso provido. A excepcionalidade exigida está, por sua vez, devidamente declarada no documento em exame. O testador fez consignar expressamente que temia por sua morte na cirurgia; por isso, naquele ato, deixava se imóvel à apelante que, segundo consta, com ele vivia em regime de situação estável. Justamente a proximidade da morte dos dispoentes e a impossibilidade dele recorrer às formas ordinárias têm sido apontadas pela doutrina como exemplo de situações excepcionais autorizadoras do ato”. (TJSP, Apelação Cível 434.146—4/0-00, 7ª Câmara de Direito Privado, Rel. Des. Álvaro Passos, julgado em 21/05/2008).

${ }^{4}$ Evidencia a natureza constitutiva da sentença pois, uma vez não verificados os requisitos extrínsecos do testamento, a conclusão legal é pela invalidade do ato. Assim, somente a sentença que reconhece a excepcionalidade confere validade jurídica ao testamento hológrafo simplificado. Esta é outro exemplo paradigmático acerca da interpretação que os tribunais vêm conferindo à matéria: AÇÃO DE CONFIRMAÇÃO DE TESTAMENTO. DECLARAÇÃO DE ÚLTIMA VONTADE. AUSÊNCIA DOS REQUISITOS FORMAIS. 1. A intenção da lei é deixar cristalina a vontade do testador perante todas as pessoas presentes ao ato, não deixando espaço para manipulações e desvios por parte de quem quer que seja. 2. Sendo desatendidos os requisitos formais do ato de disposição de última vontade, resta comprometida a sua validade, mormente quando não apontada na cédula qualquer circunstância excepcional. Recurso desprovido. (Apelação Cível No 70064477136, Sétima Câmara Cível, Tribunal de Justiça do RS, Relator: Sérgio Fernando de Vasconcellos Chaves, Julgado em 26/08/2015). 
demais hipóteses de testamento especial? Quais as repercussões jurídicas desta indefinição? Tentaremos começar a traçar as linhas iniciais destas respostas nos tópicos seguintes.

\section{TESTAMENTO HOLÓGRAFO SIMPLIFICADO E TESTAMENTOS ESPECIAIS: PONTOS DE APROXIMAÇÃO E DIFERENÇAS}

De modo a possibilitar a análise dos fatores que aproximam, e também aqueles que afastam, o testamento hológrafo simplificado dos testamentos especiais típicos, estudaremos os traços gerais das modalidades aeronáuticas, marítimas e militares de testar.

Os testamentos especiais, também chamados de extraordinários e excepcionais, tem como objetivo possibilitar que o sujeito que se encontra em situação anormal possa se valer de método simplificado de disposição patrimonial testamentária, sem a qual não poderia ou seria de extrema dificuldade a utilização de quaisquer das vias ordinárias (VELOSO, 2004).

Diferentemente das ordinárias, as formas especiais de testamento não são escolhidas livremente pelo autor do testamento, mas vinculado à circunstâncias e situações fáticas previamente fixadas pelo ordenamento jurídico. Por se tratarem de situações específicas, cujo fator tempo ganha especial relevância, é traço comum a redução das solenidades (GONÇALVES, 2012, p. 305). Neste sentido, se for tripulante, passageiro ou o próprio comandante que se encontre em navio nacional de guerra ou mercante, é obrigatório o uso do testamento marítimo; se em aeronave comercial ou militar, o aeronáutico, e; se em guerra ou em campanha, em praça sitiada ou se estejam interrompidas as comunicações, o militar.

É também peculiar o fato de que todas as modalidades testamentárias especiais, como consequência da diminuição das formalidades e da dúvida que se instaura acerca da clara intenção de testar (caso não tivesse ocorrido a situação excepcional o autor do testamento, de fato, teria testado?), o Código Civil estabelece prazo decadencial de noventa dias, contados a partir da superação da situação excepcional, para cada uma das modalidades de testamento especial. Após este prazo, cabe ao autor elaborar testamento por uma das vias ordinárias.

A única ressalva, Dias (2015, p. 376-380),

É o testamento militar quando observado o procedimento previsto no artigo 1.894 do Código Civil, que é a apresentação aberto ou cerrado, datado e assinado, perante duas testemunhas, entregue ao auditor ou à pessoa que ocupe patente correspondente.

Revista de Direito de Família e Sucessão | e-ISSN: 2526-0227 | Salvador | v. 4 | n. 1 | p. 56-70 | Jan/Jun. 2018 
Nota-se que, ainda que simplificado o procedimento, em todas as modalidades testamentárias especiais, é marcante a presença de testemunhas. O artigo 1.888 do Código Civil estabelece que o testamento marinho e o aeronáutico dependem da presença de duas testemunhas. Já o militar, conforme já exposto no tópico anterior, exige a legislação vigente de duas testemunhas, caso o autor do testamento saiba escrever, e, caso não saiba, três testemunhas. Ainda, o testamento militar nuncupativo igualmente exige a presença de duas testemunhas (SILVA, [s/d]).

Fixadas as características que identificam os testamentos especiais, é possível identificar quais aspectos se aproximam e quais se distanciam do testamento holográfico simplificado.

Inequivocamente, ambos refletem modalidades testamentárias onde se verifica a flexibilização do excesso de solenidade comumente verificado nos testamentos ordinários. Não por condolência do legislador, mas que se justifica diante do eminente risco de vida do autor do testamento.

Todavia, o instrumento particular excepcional não limita as hipóteses de excepcionalidade, tal qual fixadas nas hipóteses testamentárias especiais. Tratamos de demonstrar no tópico anterior que o autor do testamento hológrafo simplificado deve descrever a situação tida como excepcional e a avaliação de risco fica sob o sentir do juízo competente pela confirmação do instrumento.

Outra diferença entre os institutos é que a presença de testemunhas é completamente dispensada no testamento particular excepcional, enquanto que em todas as modalidades especiais de testamento, há a exigência de ao menos duas testemunhas como forma de garantir a validade do negócio jurídico.

Ainda, o legislador deixou de designar prazo decadencial para o testamento particular excepcional, não fazendo qualquer menção aos noventa dias comumente verificados nos testamentos especiais.

Assim, ainda que o testamento hológrafo simplificado seja uma hipótese com pouquíssimos requisitos e seja, de fato, uma modalidade excepcional de testamento, inclinamonos a concordar com Dias (2015) que não se trata de uma das hipóteses de testamento especial. Arremata a autora lembrando que "se houver a possibilidade de ser feito o testamento marítimo, aeronáutico ou militar, não cabe o uso do testamento excepcional” (Ibidem, p. 377). 
Este posicionamento, contudo, não é unanime. Gonçalves (2012), Veloso (2004), Dias (2014) dentre outros entendem que, ainda que guarde diferenças, é, em verdade, uma nova modalidade de testamento especial.

Trata-se, em verdade, de nova modalidade de testamento especial, na qual se exige que a excepcionalidade seja declarada na cédula. Não se admite que esta seja redigida por meios mecânicos, pois deve ser elaborado "de próprio punho e assinado pelo testador" (GONÇALVES, 2012, p. 290).

Prevê o art. 1.879 que em circunstâncias excepcionais declaradas na cédula, o testamento particular de próprio punho e assinado pelo testador, sem testemunhas, poderá ser confirmado, a critério do juiz.

Este dispositivo foi sugerido também pelo Professor Miguel Reale ao senador Josaphat Marinho, tendo sido objeto da Emenda n. 483-R, que foi aprovada. Trata-se de uma inovação, e muito importante. O que regula, na verdade, não é um subtipo, uma subespécie de testamento particular, porém, uma outra forma de testamento especial (VELOSO, 2004).

A despeito de esposarem o entendimento supra, ambos os autores acabam por afirmar, de forma contraditória, que o artigo 1.887 do Código Civil reflete rol taxativo das hipóteses de testamentos especial, que incluem somente as modalidades marítima, aeronáutica e militar.

O Código Civil de 2002 regula três formas de testamentos especiais: o marítimo, o aeronáutico e o militar (arts. 1.886 a 1.896). E, no art. 1.887, declara peremptoriamente "Não se admitem outros testamentos especiais além dos contemplados neste Código” (GONÇALVES, 2012, p. 306).

Os testamentos ordinários são três, e só três: o público, o cerrado e o particular (art. 1.862). E três, somente, são os testamentos especiais: o marítimo, o aeronáutico e o militar (art. 1.886). O art. 1.887 menciona que não se admitem outros testamentos especiais, além dos contemplados no Código Civil, o que se aplica, igualmente, aos testamentos ordinários (VELOSO, 2004).

Pablo Stolze e Rodolfo Pamplona endossam o coro dos juristas que afirmam que o artigo 1.887 do Código Civil traz rol taxativo quanto as formas de testamentos especiais, de modo que excluem o testamento hológrafo simplificado desta relação (GAGLIANO, 2016, p. 313).

Sem a intenção de alongar as discussões acerca da natureza do rol descrito no parágrafo anterior ser, ou não, taxativo, uma vez que não é o objeto deste artigo, inclinamo-nos a 
acompanhar o entendimento de Dias (2015), como já apontado. Ainda que o testamento particular excepcional seja uma modalidade com procedimentos reduzidos e que dependa de circunstâncias igualmente excepcionais, não se confunde com nova modalidade de testamento especial, mas uma forma especial de testamento ordinário, qual seja, o particular.

Fixadas estas premissas, há comentário crítico que uniu a doutrina especializada acerca do testamento hológrafo simplificado, qual seja a ausência de previsão legal de prazo de validade da disposição testamentária para a hipótese de que, uma vez superada a situação excepcional, em sobrevivendo o autor do testamento, caso este não teste por uma das formas ordinárias, a validade do testamento seria prejudicada, a exemplo do quanto previsto para as modalidades especiais. Este aspecto ganha especial relevo quando a VII Jornada de Direito Civil aprova o Enunciado ${ }^{\circ} 611$, com a seguinte redação:

ENUNCIADO 611- O t O testamento hológrafo simplificado, previsto no art. 1.879 do Código Civil, perderá sua eficácia se, nos 90 dias subsequentes ao fim das circunstâncias excepcionais que autorizaram a sua confecção, o disponente, podendo fazê-lo, não testar por uma das formas testamentárias ordinárias.

Considerando acreditarmos que o testamento hológrafo simplificado não é uma das modalidades de testamento especial, há fundamento legal que permita explicar a incidência do prazo decadencial de noventa dias nesta via testamentária?

\section{HÁ POSSIBILIDADE DE INCIDÊNCIA DO PRAZO DECADENCIAL NO HOLÓGRAFO SIMPLIFICADO?}

Desde a inserção do testamento hológrafo simplificado no ordenamento jurídico pátrio, a doutrina especializada salienta que foi recebida com surpresa a opção legislativa de não prever prazo decadencial para esta modalidade testamentária, tal qual o que vigora para os testamentos especiais.

Fundamento comum é o de que, uma vez superada a excepcionalidade que justifica se valer de via testamentária igualmente excepcional, o interessado em testar deveria se valer de uma das formas ordinárias. Veloso (2004) sustenta que "vencidas ou superadas as circunstâncias extraordinárias, não é razoável que se mantenha, indefinidamente, a forma privilegiada, excepcional que foi utilizada numa emergência”. 
Gonçalves (2012), para fundamentar a necessidade de que se implemente prazo de caducidade para o testamento hológrafo simplificado, se vale da doutrina estrangeira que inspirou o legislativo para incluir esta modalidade no ordenamento jurídico pátrio.

A maioria das legislações, como o código Napoleão (art. 987), Código Civil espanhol (art. 703), Código Civil suíço (art. 508), Código Civil italiano (art. 610), por exemplo, que admitem testamento hológrafo de forma simplificada nas hipóteses em que o testador se acha em perigo iminente de morte, ou em caso de epidemias, moléstias contagiosas, interceptação de comunicação, etc., determina a perda da eficácia do testamento se passar algum tempo da cessação da causa que impediu o testador de valer-se de formas ordinárias (GONÇALVES, 2012, p. 290).

Em harmonia com o já relatado no tópico anterior, na VII Jornada de Direito Civil restou aprovado enunciado que sugere que seja aplicado prazo decadencial de noventa dias ao testamento hológrafo simplificado, a exemplo do que ocorre com os testamentos especiais. Quando da apresentação da justificativa, consolidou-se as seguintes razões:

O testamento é negócio jurídico eminentemente solene. O ordenamento jurídico prevê diversas solenidades específicas para cada forma testamentária ordinária ou especial, visando à salvaguarda da liberdade de testar e à preservação da autenticidade das manifestações de vontade do testador. Excepcionalmente, o Código Civil permite que, em circunstâncias extraordinárias (que deverão ser declaradas na cédula), o disponente elabore testamento particular de próprio punho sem a presença de testemunhas. As formalidades são flexibilizadas em função da excepcionalidade da situação em que se encontra o testador, permitindo-se que este exerça sua manifestação de última vontade. Ocorre que, em se verificando o desaparecimento das mencionadas circunstâncias extraordinárias, não se justifica a subsistência do testamento elaborado com mitigação de solenidades. Destaque-se que esta é a regra aplicável para as formas especiais de testamento (marítimo, aeronáutico e militar), para as quais, de modo geral, aplica-se um prazo de caducidade de 90 dias, contados a partir da data em que se faz possível testar pelas formas ordinárias. Por essa razão, conclui-se que, não havendo mais o contexto de excepcionalidade, o testamento hológrafo simplificado perde sua razão de ser, devendo o testador se utilizar de uma das formas testamentárias revestidas das devidas e necessárias solenidades.

Veloso (2004) já sustentava a aplicação deste prazo, afirmando que:

$\mathrm{O}$ art. 1.879 devia apresentar um parágrafo único, que previsse: “O testamento referido neste artigo caducará noventa (90) dias depois de cessadas as circunstâncias 
excepcionais, se o testador, podendo, não tiver feito outro testamento, na forma ordinária”.

Ocorre que, as bases que fundaram o entendimento retro esposado sofreram graves abalos, principalmente diante das severas críticas que a ineficiência desta modalidade de deixa pós morte.

A despeito de concordarmos com a necessidade de limitação temporal das manifestações de vontade expressadas em condições excepcionais, que por vezes acarretam exageros não comedidos pelo risco da morte, nos inclinamos a crer que estabelecer prazo decadencial em modalidade testamentária que o legislador optou por não fixar é andar na contramão das novas perspectivas doutrinárias acerca do direito sucessório. Em cenário que a aferição da clara manifestação de vontade do autor do testamento tende a se dar com a mínima solenidade possível, atrair mais uma hipótese de anulabilidade da disposição de última vontade não nos parece ser a melhor solução.

Hironaka (2017) nos lembra o rol excessivo de formalidades essenciais, que se não observadas conduzirão à nulificação do ato, contribuem para o fato de existir no Brasil a baixa confecção de testamento, algo próximo a somente dois por cento da população. San Tiago Dantas ao comparar o formalismo do testamento e o do casamento, ambos os atos solenes, explica, que:

Em matéria de casamento a omissão de formalidades extrínsecas só conduz à nulidade muito raramente, dado o favor matrimonii com que se examinam todas as nulidades, em matéria de testamento, ao contrário, a omissão das formalidades reputadas essenciais pela lei, conduz com frequência, ao aniquilamento do ato (DANTAS, 1991, p.505).

A favor testamenti, que historicamente foi trabalhada somente como elemento jurídico apto a preservar disposições testamentárias ambíguas, atualmente, com o objetivo de corrigir o excesso de formalismo e de evitar a perda da última manifestação de vontade, vem sendo aplicado para mitigar, também, a forma do ato. Este movimento iniciado pela doutrina vem ganhando espaço já nos tribunais, havendo manifestação clara do Superior Tribunal de Justiça se valendo deste princípio para abrandar as exigências formais ${ }^{5}$.

${ }^{5}$ Eludicidativa é a lição do Tribunal do Rio Grande do Sul. Neste sentido: Ementa. APELAÇÃO. ANULATÓRIA DE TESTAMENTO. IMPROCEDÊNCIA. ADEQUAÇÃO. A doutrina e a jurisprudência (desta Corte e do STJ) têm admitido um certo abrandamento nas formalidades previstas para o testamento, como forma de preservar a 
Contudo, as formalidades no Código Civil de 2002 - assim como na jurisprudência, pautada numa interpretação mais atenta à finalidade do negócio jurídico (princípio favor testamenti) - vêm sendo aos poucos mitigadas para facilitar a elaboração do testamento, sem desrespeitar a observância fiel do ato do testador e o cumprimento da sua última vontade na sucessão. Garante-se, assim, o direito constitucional à herança, insculpido no art. 5º XXX da Carta Magna (DIAS, 2014).

Em um cenário em evolução, que começa a dar os primeiros sinais de superação do panorama passado, onde:

As formalidades que cercam a facção dos testamentos, sejam eles públicos, particulares ou cerrados, são tantas e de tanto preciosismo que esta bem pode ser também uma causa a afastar de nós, brasileiros, a decisão de testar não parece dispor de solo fértil para novas restrições taxativas e prejudiciais à favor testamenti (HIRONAKA, 2017).

Neste sentido, acreditamos que a melhor alternativa seria se pensarmos o prazo, ainda que de noventa dias proposto, como parâmetro impróprio, se se pensar que adotar fluxo temporal é a melhor opção. A proposta é que o prazo de noventa dias não seja interpretado como limite pré-estabelecido de extinção do direito, mas como um parâmetro facilitador da atividade jurisdicional. Um prazo impróprio, portanto.

Isto posto, concordamos com Gonçalves (2012), Dias (2015), Veloso (2004), dentre outros, quanto a necessidade de não eternizar os testamentos formulados em situações excepcionais, quando o autor do testamento sobrevive à excepcionalidade, pois o testamento depende, sobretudo, da clara manifestação de vontade da parte sobre o que deseja dispor da fatia disponível do seu patrimônio. Sem embargo, atrair para uma modalidade especial de testamento ordinário o prazo decadencial típico dos testamentos especiais, sem que a Lei assim tivesse disposto, não nos parece a solução adequada ao problema.

\section{CONSIDERAÇÕES FINAIS}

manifestação de última vontade do testador. Caso de validade do testamento, no qual um parente da testadora atuou como testemunha. Inexistência de dúvidas quanto à vontade da falecida. NEGARAM PROVIMENTO. (Apelação cível n ${ }^{\circ}$ 70039479654, Oitava Câmara Cível, Tribunal de Justiça do RS, Relator: Rui Portanova, Julgado em 28/04/2011). 
O direito sucessório, enquanto ramo do direito privado permaneceu em berço esplendido, resistente às mudanças do pensar sobre o direito civil que reformaram o nosso sistema a partir do século vinte, substituindo o ideário liberalista e patrimonialista do direito pelo social e igualitário. Não ter acompanhado este movimento de transição fez com que o livro de sucessões esteja vivendo em um ambiente legislativo com o qual pouco, ou quase nada, se comunica.

Há, contudo, esforço doutrinário recente que visa atualizar os dispositivos atinentes à matéria, não se limitando a fazer pressão para reforma legislativa, mas revisitando os institutos por meio de um novo olhar. É decorrência deste novo paradigma interpretativo a nova roupagem ao princípio do favor testamenti, de modo que, onde anteriormente era invocado somente para sanar ambiguidades, hoje é possível mitigar os excessos da formalidade em sede testamentária, como forma de preservar a manifestação de vontade do autor do testamento.

No que tange ao testamento, elemento abraçado por todas estas mudanças, modalidade de negócio jurídico que não se disseminou na cultura popular, cuja inexpressividade se relaciona com o excesso de formalismo, abraçar a dissolenização do direito sucessório e pregar pela preservação da manifestação de última vontade é uma das alternativas para evitar que esta espécie de planejamento sucessório caia em desuso. Em especial ante a novas tecnologias jurídicas com finalidade semelhante, a exemplo da Holding Patrimonial.

Neste sentido, figuras como o testamento particular excepcional, instituto jurídico sucessório que reúne o menor número de requisitos para que seja confeccionado, assim deve permanecer.

Sem a pretensão de questionar o clamor dos juristas especializados, que desde a introdução do testamento hológrafo simplificado no direito brasileiro requerem a fixação de prazo que determine a validade da disposição testamentária excepcional após a superação do evento que possibilitou a facção do instrumento, não nos parece adequado fixar prazo decadencial para uma situação jurídica que a própria Lei não conferiu. Pensar em atrair outra hipótese verificável de anulação da disposição testamentária excepcional é, ao nosso sentir, andar na contramão dos novos guias que iluminam o direito sucessório.

Sem embargo, a manifestação dos participantes que aprovaram o enunciado 611 na VII Jornada de Direito Civil é de grande valia para o estudo do instituto. Ainda que entendamos que estabelecer prazo decadencial de noventa dias para o testamento holográfico especial não seja o caminho adequado, certamente este pode funcionar como um guia para diminuirmos a álea interpretativa do julgador que decidirá sobre a confirmação, ou não, do testamento particular. 
A proposta é, portanto, que os testamentos particulares excepcionais que tenham sido apresentados à confirmação dentro do prazo de noventa dias, verificada a excepcionalidade da circunstância, tenham o pedido deferido. Quanto àqueles que não tenham sido apresentados até o nonagésimo dia, se próximo a isso, também sejam deferidos, observadas as especificidades do caso concreto. Com efeito, é pensar o marco temporal de noventa dias como um guia, e não como um limitador do direito de dispor do patrimônio.

\section{REFERÊNCIAS}

CONSELHO da Justiça Federal. VII Jornada de Direito Civil. Enunciado 611. CJF ENUNCIADOS. Disponível em: <http://www.cjf.jus.br/enunciados/enunciado/847>. Acesso em: 27 ago. 2017.

DANTAS, San Tiago. Direito de Família e das Sucessões. 2.ed. Rio de Janeiro: Forense,1991.

DIAS, Juliana Estevão Lima. Do testamento particular: Direito das Sucessões (Art. 1.857 e seguintes do Código Civil de 2002). Publicado em: 07 jul. 2014. Disponível em: $<$ http://www.boletimjuridico.com.br/m/texto.asp?id=3602>. Acesso em: 26 ago. 2017.

DIAS, Maria Berenice. Manual das sucessões. 4.ed. São Paulo: Revista dos Tribunais, 2015.

GAGLIANO, Pablo Stolze; PAMPLONA FILHO, Rodolfo. Novo curso de direito civil. V.7. 3.ed. São Paulo: Saraiva, 2016.

GONÇALVES. Carlos Roberto. Direito Civil Brasileiro. Direito das sucessões. V.7. 6.ed. São Paulo: Saraiva. 2012.

HIJAZ, Tailine Fátima. Testamentos e codicilos: breves considerações à luz do ordenamento jurídico brasileiro. Revista de Direito dos Monitores da UFF - n. ${ }^{\circ} 14$ de 2013. Disponível em: < http://www.rdm.uff.br/index.php/rdm/article/view/179/122>. Acesso em: 17 ago. 2017.

HIRONAKA, Giselda Maria Fernandes Novaes. A forma como foi disciplinada a sucessão testamentária em nosso país é um obstáculo para a maior utilização do ato de última vontade 


no Brasil? Ano 3 (2017), $\quad \mathrm{n}^{\mathrm{o}} \quad 1$, 413-422. $\quad$ Disponível em:

$<$ http://www.cidp.pt/publicacoes/revistas/rjlb/2017/1/2017_01_0413_0422.pdf>. Acesso em: 29 ago. 2017.

SANTOS, Ernane Fidélis dos. Manual de direito processual civil. Procedimentos especiais codificados e da legislação esparsa, jurisdição contenciosa e jurisdição voluntária. 14.ed. São Paulo: Saraiva, 2016.

SILVA, Sérgio Viana da. As formas testamentárias no direito brasileiro. Disponível em: $<$ http://scholar.googleusercontent.com/scholar?q=cache:5t3x5DV_PQcJ:scholar.google.com/+sergio+ viana+da+silva.+testamento\&hl=pt-BR\&lr=lang_pt\&as_sdt=0,5>. Acesso em: 29 ago. 2017.

TARTUCE, Flávio. Manual de direito civil: volume único. Rio de Janeiro: Forense; São Paulo: Método, 2011.

TARTUCE, Flávio. O estatuto da pessoa com deficiência e a capacidade testamentária ativa. Ano 2 (2016), nº 6, 521-561. Disponível em:

<http://www.cidp.pt/publicacoes/revistas/rjlb/2016/6/2016_06_0521_0561.pdf \. Acesso em: 07 jul. 2017.

VELOSO, Zeno. Testamentos - noções gerais; formas ordinárias; codicilo; formas especiais. In: HIRONAKA, Giselda Maria Fernandes Novaes; PEREIRA, Rodrigo da Cunha (coord.) - Direito das sucessões e o Novo Código Civil. Belo Horizonte: Del Rey, 2004. Disponível em:

<www.flaviotartuce.adv.br/assets/uploads/artigosc/zeno_testamento.doc>. Acesso em: 20 ago. 2017. 